\title{
Effects of Fog in a Brazilian Road Segment Analyzed by a Driving Simulator for Sustainable Transport: Drivers' Speed Profile under In-Vehicle Warning Systems
}

\author{
Felipe Calsavara ${ }^{1, *(\mathbb{D}}$, Felipe Issa Kabbach, Jr. ${ }^{2}$ and Ana Paula C. Larocca ${ }^{1} \mathbb{D}$ \\ 1 Department of Transportation Engineering, São Carlos School of Engineering (EESC), \\ University of São Paulo (USP), São Carlos 13566-590, Brazil; larocca.ana@usp.br \\ 2 Department of Transportation Engineering, Polytechnic School, University of São Paulo (USP), \\ São Paulo 05508-070, Brazil; felipe.kabbach@usp.br \\ * Correspondence: felipe.calsavara@usp.br; Tel.: +55-16-3373-9604
}

check for updates

Citation: Calsavara, F.; Kabbach, F.I., Jr.; Larocca, A.P.C. Effects of Fog in a Brazilian Road Segment Analyzed by a Driving Simulator for Sustainable Transport: Drivers' Speed Profile under In-Vehicle Warning Systems. Sustainability 2021, 13, 10501. https:// doi.org/10.3390/su131910501

Academic Editors: María Castro and Keila González-Gómez

Received: 30 June 2021

Accepted: 10 September 2021

Published: 22 September 2021

Publisher's Note: MDPI stays neutral with regard to jurisdictional claims in published maps and institutional affiliations.

Copyright: (c) 2021 by the authors. Licensee MDPI, Basel, Switzerland. This article is an open access article distributed under the terms and conditions of the Creative Commons Attribution (CC BY) license (https:/ / creativecommons.org/licenses/by/ $4.0 /)$.

\begin{abstract}
Intelligent transport systems enable vehicles to communicate with each other and with the environment, ensuring road safety. Their implementation can help reduce the number of accidents, especially in stretches of s-curves, where speed control is essential to ensure the safety of drivers, and under hazardous weather conditions. Such systems promptly notify drivers about potentially dangerous road conditions, such as fog, so that they can better adapt their driving behavior. This study evaluates the driver's speed profile in different scenarios (clear weather, fog weather, and fog with an in-vehicle fog warning system) considering the road geometry elements (s-curves). A driving simulator recreated the real scenarios of a principal Brazilian road segment, showing the geometric and weather conditions of a road known for its several s-curves and frequent incidence of fog. A preliminary study identified the most critical curves through a weighted severity index methodology to define the critical segment. The results showed drivers considerably reduced their speed in the scenario with a warning system, thus contributing to the safety of s-curved segments. The implementation of in-vehicle warning systems can avoid or reduce the need for major infrastructure interventions such as geometric design, through investments in new intelligent transport systems.
\end{abstract}

Keywords: connected-vehicle; driving simulator; fog; speed profile; warning-system

\section{Introduction}

Intelligent Transport Systems (ITS), based on connected vehicles communication, help drivers take actions from externally acquired information by, for example warning them of a potentially dangerous situation to be avoided by automatic braking or automatic steering. The development of information technology promotes traffic efficiency and safety through real-time information interaction between vehicles (V2V) and vehicles and infrastructure (V2I).

External factors like weather conditions impact roadway situations and traffic safety [1], and adverse phenomena, such as fog reduce visibility, contributing to traffic crashes. Fog increases the risk of accidents since it hides long-range visual information and hampers the prediction of the path to be taken and events (e.g., pileups or vehicle decelerations) [2].

In Brazil, according to the annual traffic statistics of road traffic crashes issued by the federal highway patrol, fog was a probable cause for 11,753 accidents between 2011 and 2020 , which represent $5 \%$ of the total number of crashes occurred under adverse weather conditions (rain, fog, snow, strong wind, etc.) [3]. Although the percentage of accidents under fog is smaller than those under normal visibility conditions, they tend to be more severe and involve multiple vehicles $[1,4,5]$.

According to Mueller and Trick [6], reduced visibility increases the risk of collision. However, not all drivers are affected in the same way-some are more likely to make 
safety-related adaptations, which can be measured primarily by speed compensation and ability to follow a car or stay in the lane. Speed compensation is the most typical adjustment to driving behavior under fog conditions. Previous studies have confirmed drivers tend to make safety-related adaptations, such as slowing down, to compensate for insecurity due to the limited visual field $[7,8]$.

However, a study with a driving simulator conducted by Yan et al. [9] confirmed driver's reduction in speed under low-visibility conditions is not enough to respond in time to impending changes in road geometries, speed variation of vehicles ahead, and an emergency event. Although some drivers would keep longer headway distances, rear-end crashes may still occur, since they may not be able to see the breaking lights of the front vehicle [10].

Efforts have been devoted to solving the traffic safety problems in a fog area. The warning system that alerts drivers about a fog location helps them improve their speed adjustment before entering the fog zone. The most typical warning systems that provide drivers with real-time traffic alerts are located in the highway infrastructure Dynamic Message Sign (DMS), and inside Connected Vehicles (CV), called in-vehicle information systems. Liu and Khattak [11] claim vehicles sharing their status information with other vehicles or with the infrastructure leads to better-planned actions during driving, earlier identification of hazards, and safer responses.

Several studies on DMSs in fog situations have been conducted. Using a driving simulator, Boyle and Mannering [12] analyzed drivers' speed adjustments under four different scenarios of advisory information under foggy conditions. According to the findings, although warning messages lead to significant speed reductions in the lowvisibility area, drivers tend to increase speed downstream, when such adverse conditions no longer exist. Al-Ghamdi [13] studied traffic crashes caused by fog and concluded although the DMS warning system was ineffective in reducing speed variability, the mean speed was reduced by approximately $6.5 \mathrm{kph}$ in fog sections. Wu et al. [10] conducted an empirical driving simulator study to assess the effectiveness of real-time fog warning systems, and the results showed drivers are more likely to reduce their speed or brake harder under thicker fog.

In recent years, due to the significant development of CV technology, investigations into the effectiveness of V2V systems have increased. Zhao et al. [14] used a connected vehicle test platform to analyze the speed adjustment of drivers after receiving warning information at different fog concentrations. The results indicated the warning system effectively led to speed reductions in all fog scenarios. Chang et al. [15] used a fixedbased driving simulator to investigate the effectiveness of fog warning systems in driving performance. According to the results, scenarios with fog warning systems significantly improved safety due to speed reduction prior to a fog area over the no warning system scenario. Wu et al. [16] conducted a driving simulator study to evaluate the effectiveness of the Head-Up Display (HUD) warning system in drivers' braking behaviors. The results indicated the system can help decrease drivers' reaction time and reduce the probability of accidents.

The information exchange between the CV technology and the driver is critical content to be studied, especially due to the benefits it can offer to highway management, reducing investments for the elimination of stretches with high accident indexes like s-curves (i.e., complex curves with a generally small radius and short tangent) [17].

The road geometry of curves is complex, thus hampering driving and often violating a driver's expectations. Milosevic and Milic [18] investigated drivers' perception of vehicle speed in curves and reported drivers tend to underestimate their speed. Speed underestimation on curved roads can significantly contribute to sudden speed variations, hence, accidents. Good accident-prevention measures must, therefore, be selected according to the characteristics of the curves for preventing drivers from misperceiving their speed. 
Although previous studies have analyzed the effects of fog warning systems on drivers' speed maneuvers, few have compared drivers' behaviors while driving in curved segments in different weather scenarios.

Multiple ADAS implementation positively impacts drivers' behavior but still lacks the ability to address some issues when there is foggy weather condition by assessing the relationship between human behavior and a single ADAS (fog warning system). This research analyzes the effects of an in-vehicle fog warning on a driver's speed profile on a stretch of road with critical geometric (s-curves) and weather (fog) conditions. An experiment conducted in a driving simulator considered the benefits of its use since it helps evaluations of the effectiveness of inclement weather warning technologies due to their capacity to provide real-world scenarios at a relatively low cost (compared to real-world experiments) and no risks to the driver's life [19].

Countries have different climates, traffic compositions, and road geometries, and these different characteristics may influence driving behavior. A broad understanding of low visibility driving behavior in different countries can help researchers and designers improve road safety through more effective safety measures. The scenarios employed were in a simulated rural Brazilian road known for its several s-curves and frequent incidence of fog. A Weighted Severity Index (WSI) methodology defined the critical segment.

\section{Methods}

\subsection{Apparatus}

The simulator is part of the Sustainable Road Safety Project of the Department of Transportation Engineering from the São Carlos School of Engineering, University of São Paulo-Brazil. It can support driving simulations in several rural traffic environments under laboratory control according to different experimental purposes and was used in previous studies [20-26]. It is comprised of a driving cockpit with a car seat, a steering wheel with paddle shift and force feedback, accelerator, brake, clutch pedals, and speakers to reproduce sounds like vehicle engines and wind (Figure 1a). A flat panel projected the simulated environment, lateral mirrors, rear mirrors, and a HUD (for speed and fog warning information).

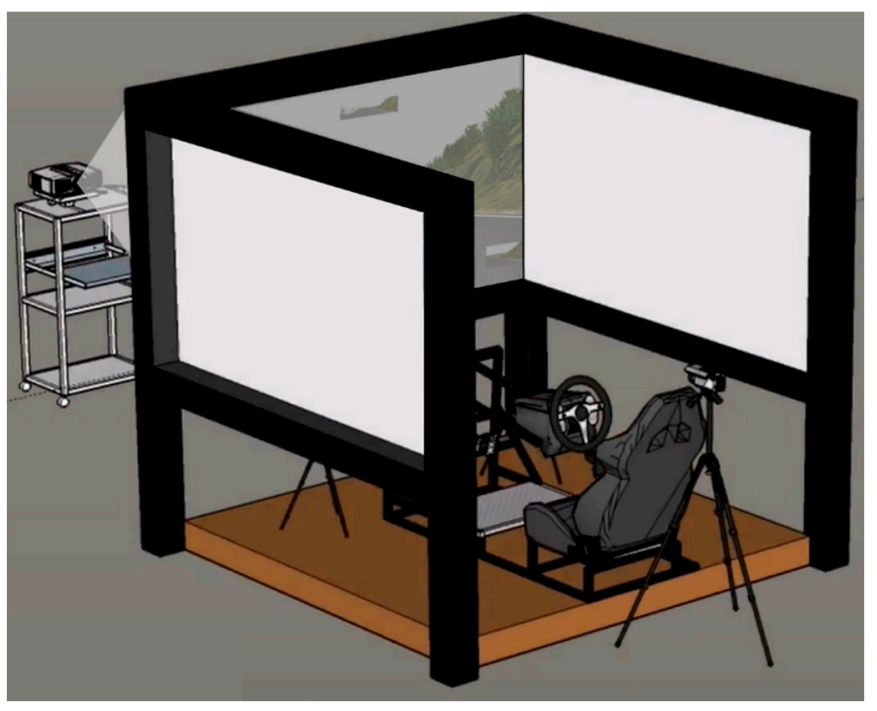

(a)

Figure 1. Cont. 


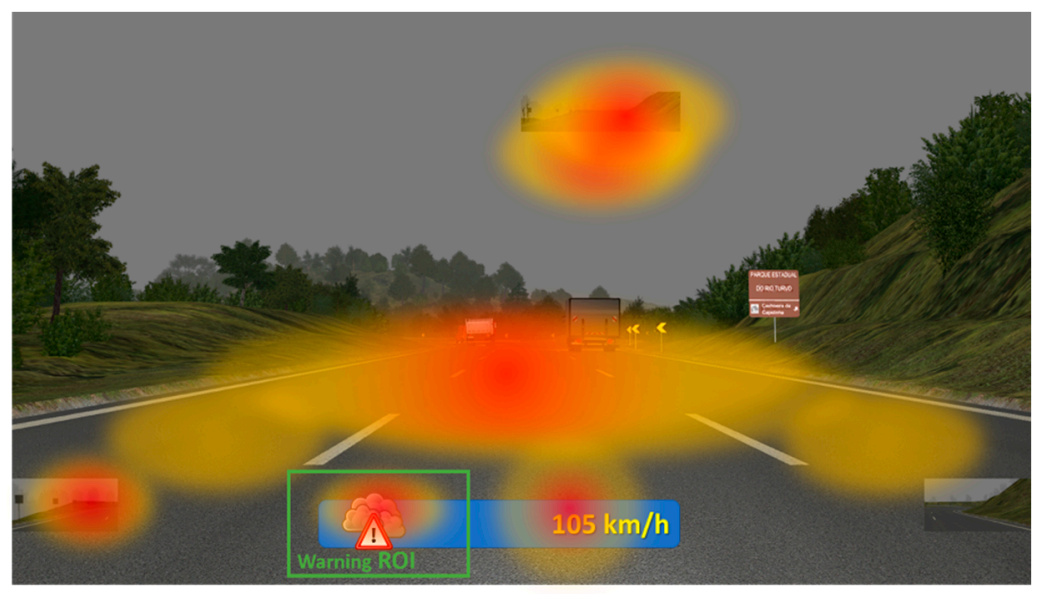

(b)

Figure 1. (a) Simulator's physical structure (scheme) and (b) representative screen and head-up display (with heat map and fog warning region of interest displayed).

Two computers process the real-time simulation-one is responsible for environment rendering and simulation running, and the other models the vehicle's dynamics, including a road-vehicle interaction and mechanical responses to the driver's actions.

In addition to the components described above, appropriate equipment-model Pro $5.10^{\circledR}$ Smart Eye-was attached to the simulator to record eye movements. Pro 5.10 is comprised of three front cameras that perform the driver's eye-tracking, and an additional rear camera, which records the scenes seen by the driver. The equipment provides raw data reliability and 3D filtered data, and remotely tracks the direction of the gaze calculated automatically based on $\mathrm{X}$ and $\mathrm{Y}$ coordinates.

MAPPS 3.3 software, developed by EyesDX (Coralville, IA), analyzed data on the eyes' movement. A frame-by-frame analysis was conducted on a video with the eye's position overlaid on the field of view to identify participants' attention allocation on HUD when the fog warning was displayed. In order to investigate how often and when the participants inspected the HUD, the fog warning region in HUD was defined as one region of interest (ROI), and only the participants whose fixation in the warning moment fell within this area were part of the sample of this research. Figure $1 \mathrm{~b}$ shows an example of the software interface, which detects the intersection of the driver's gaze with objects created in the environment for better determining the response time and maps the areas on the screen most viewed by the driver on a heat map.

\subsection{Simulated Location}

The rural road simulated is a $5 \mathrm{~km}$ stretch of an important Brazilian highway that connects Sao Paulo to Curitiba and is the primary connection between the south and southeast regions (Figure 2). The stretch is in a mountainous region with high fog incidence and a large number of s-curves in its geometry. The highway administrator provided the stretch geometric design necessary for virtual modeling, the AADT (Average Annual Daily Traffic), as well as the location, type, and severity of accidents that have occurred in recent years.

The period for the simulation was the month of June, and the time was set to 6 am, which, according to data from DPRF [3], is the most frequent period for accidents under fog weather (Figure 3). Such findings are in line with the results of Abdel-Aty et al. [27] who, in a detailed study of traffic accidents in the state of Florida (US), observed fog was the main cause of collisions in rural areas, during the winter months and in the early hours of the morning. 

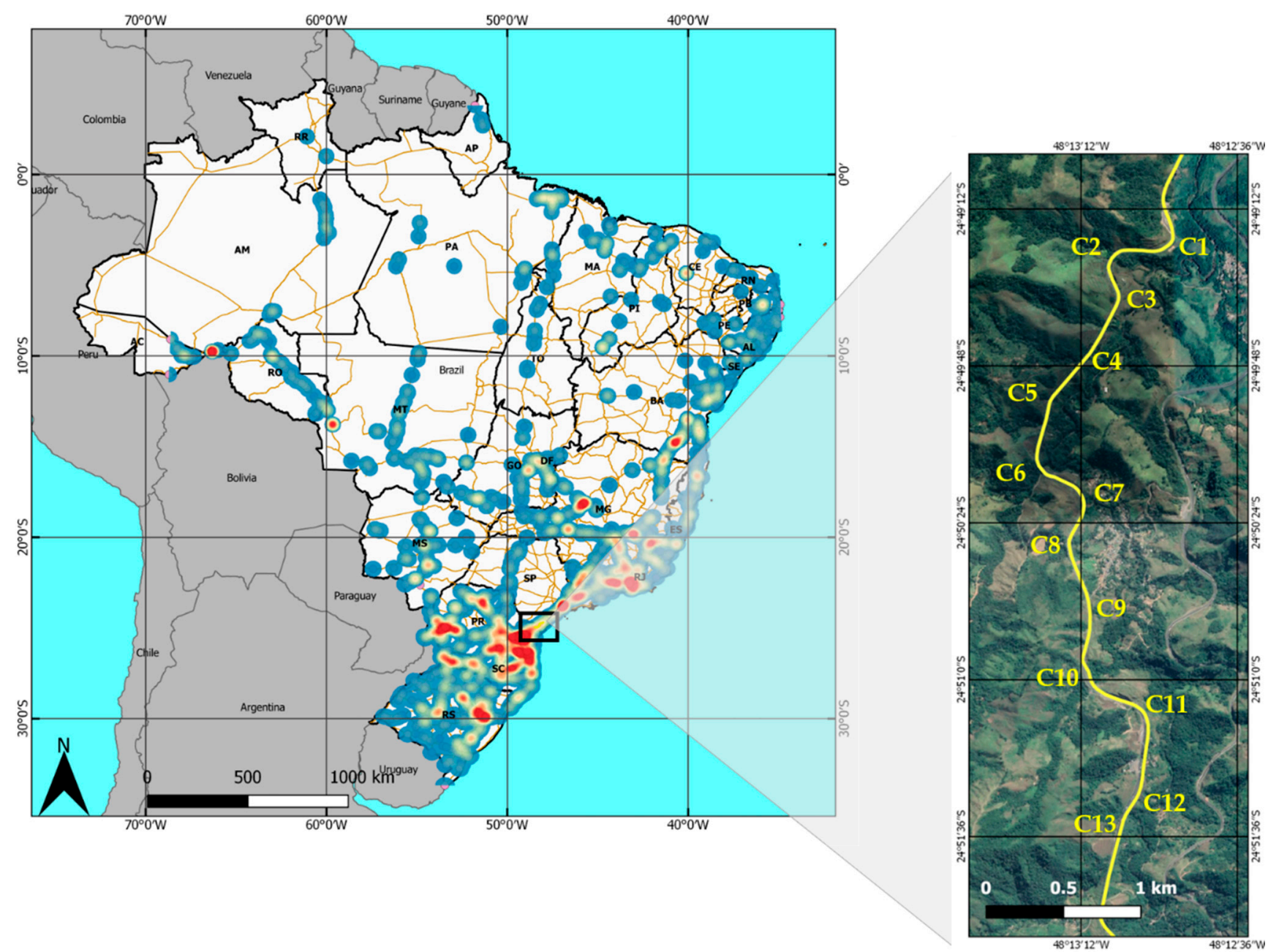

Figure 2. Distribution of accidents under fog in Brazilian federal highways, with predominance in South and Southeast regions, which together represent approximately $80 \%$ of such accidents.
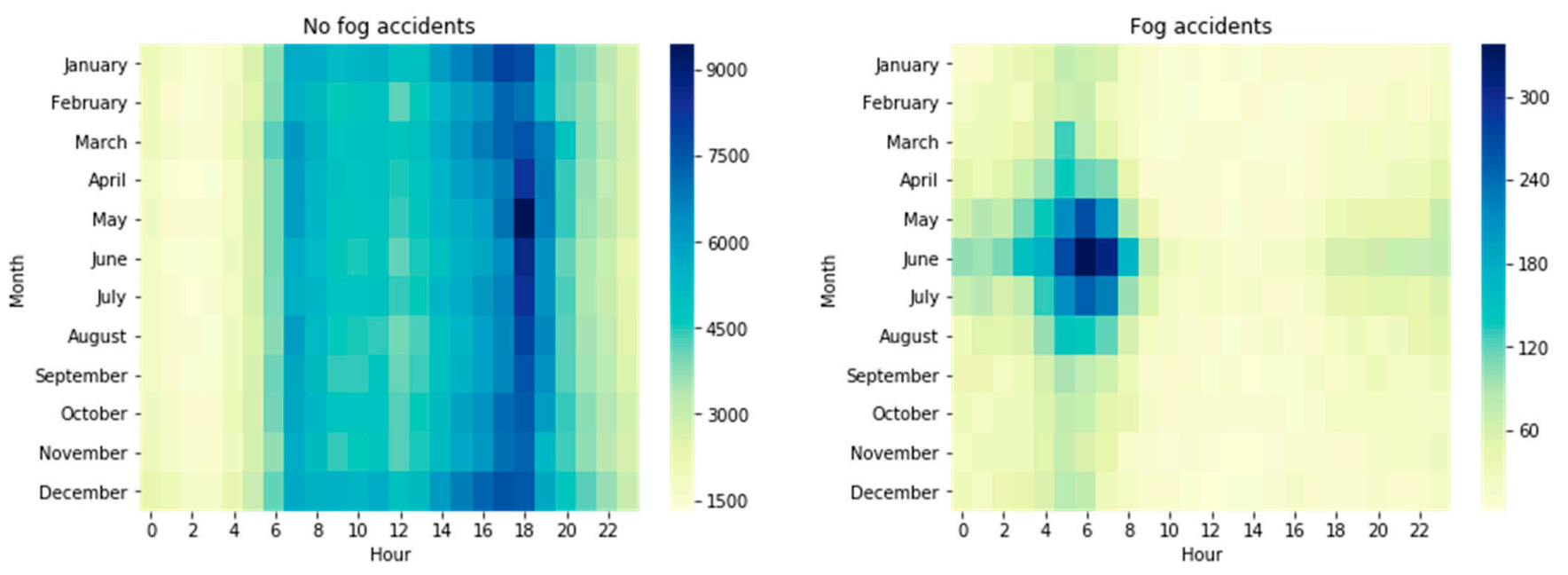

Figure 3. Distribution of accidents in Brazilian federal highways along year and day over the past ten years: under fog weather (right) and under no fog weather (left). 


\subsection{Analyses of Curve}

The $5 \mathrm{~km}$ stretch comprises 13 curves, and the fog analysis was performed in a segment selected according to the fog car crash statistics of the stretch from 2011 to 2020. The high number of traffic accidents is usually associated with inadequate driving maneuvers of the driver induced by the road geometry [17] —in this case, by the s-curves of the analyzed section.

Apart from the absolute indices of victims and/or traffic accidents, a Weighted Severity Index (WSI) methodology identified the most critical curves in the segment. WSI is a numerical method of the Brazilian National Traffic Department (Denatran) that attributes weight to the types of accidents according to the severity of the damage caused. In Brazil, Denatran [28] recommends the following weights and respective expression (Equation (1)) for determining the severity index (S), measured in UPS (Standard Severity Unit), where D, $\mathrm{V}$, and $\mathrm{F}$ represent the number of accidents with no victims (with only material damage), with non-fatal victims, and with fatal victims, respectively.

$$
\mathrm{S}=1 \times \mathrm{D}+5 \times \mathrm{V}+13 \times \mathrm{F}
$$

WSI was determined for each curve of the stretch (see Figure 4) with the accidents reported over the last ten years. The 6th curve (C6) showed a higher number of accidents and severity index. Both the curve and the posterior one (C7) are complex curves with a small radius and short tangents (previous C6 tangent length: $275 \mathrm{~m}$; C6 curve sector: $245 \mathrm{~m}$ length and $130 \mathrm{~m}$ radius; afterward C6 tangent length: $50 \mathrm{~m}$; $\mathrm{C} 7$ curve sector: $340 \mathrm{~m}$ length and $180 \mathrm{~m}$ radius), classified as s-curves.

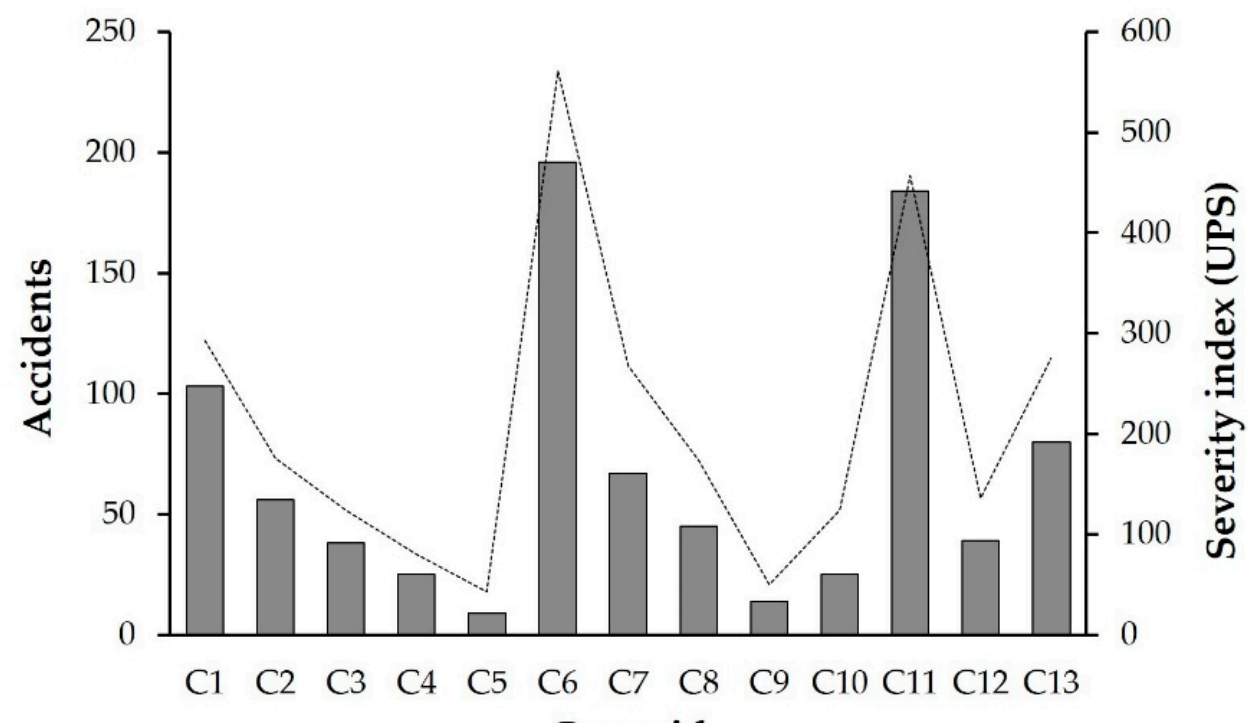

\section{Curve id}

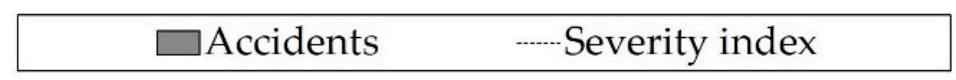

Figure 4. Car crash statistics and severity index identified by curves.

The hypothesis is that accidents are related to drivers' inability to react properly under fog conditions at those spots. According to geometry and crash statistics, the analyses of fog were performed between C6 and C7.

\subsection{Scenarios}

The scenarios were modeled and simulated by Virtual Test Drive (VTD) package developed and marketed by Vires ${ }^{\circledR}$ (Bad Aibling, Germany), according to the data collected. The data sets obtained were then analyzed by Python 3.6 programming codes. All scenarios were designed for analyses in the selected stretch, with a heavy $\mathrm{x}$ passenger car proportion 
of the traffic flow respecting the results from National Traffic Counting Plan (PNCT) [29], at 6:00 am under a cloudy sky. Traffic was deactivated prior to the driver's entering the fog study area for avoiding the influence of nearby cars.

The only changes between the scenarios were the presence or absence of fog and fog warning for ensuring differences would not be confused with other factors. Fog position (settled in the tangent between C6 and C7) and fog intensity based on visibility (50 m) were fixed in all foggy trials. Fog warning was settled $400 \mathrm{~m}$ prior to the driver's entering fog position.

Figure 5 illustrates the three scenarios analyzed, i.e., clear weather (Figure $5 a$ ), fog weather (Figure $5 b$ ), and fog weather with an in-vehicle fog warning system, referred to as "Fog\&CV" (Figure 5c).

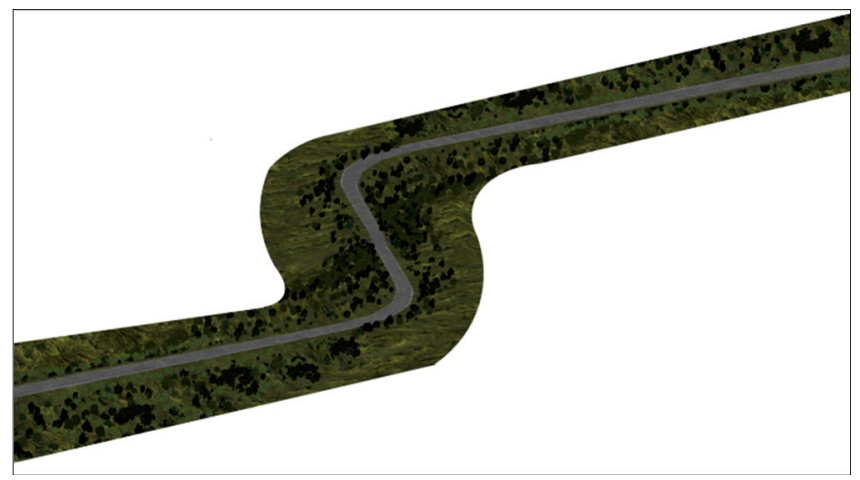

(a)

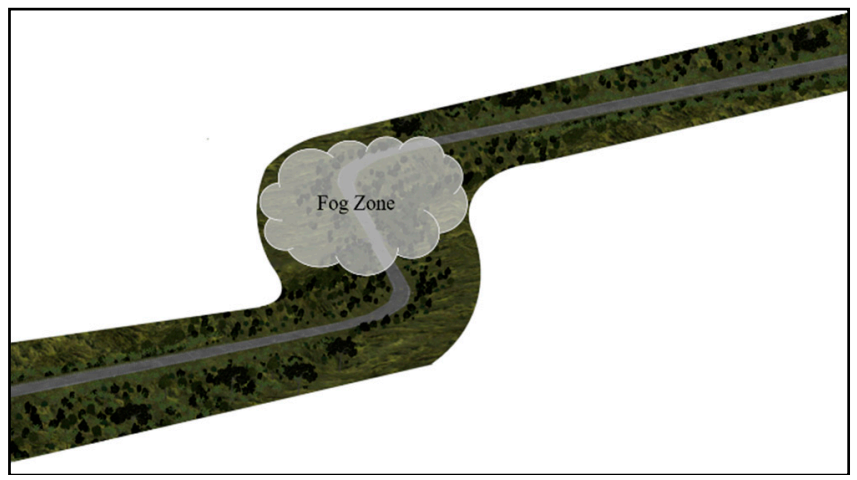

(b)

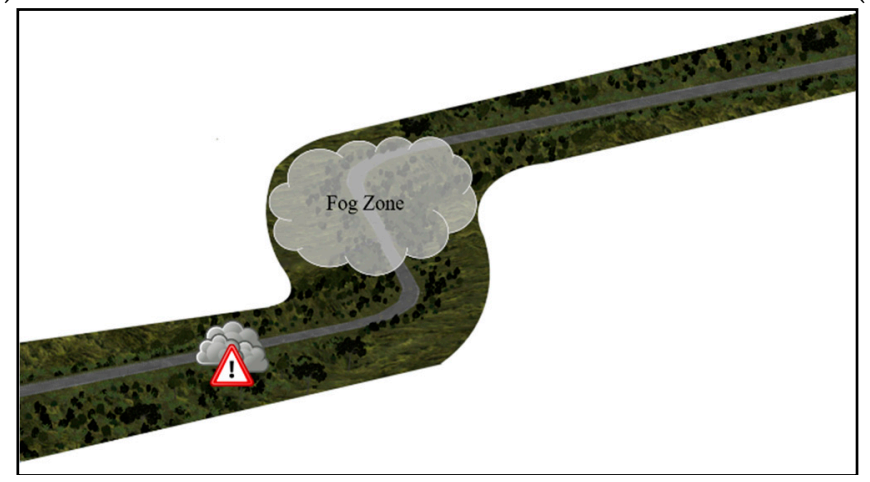

(c)

Figure 5. View of simulated C-6 and C-7 geometry scenarios. (a) clear weather, (b) fog weather, and (c) fog\&CV.

\subsection{Experimental Design and Procedure}

Trials were conducted with twenty-eight participants, who were required to have had a driver's license for at least one year and normal or corrected-to-normal vision. The group of volunteers was formed by 18 men and 10 women, aged between 21 and 33 years old $(\mathrm{M}=25.4, \mathrm{SE}=4.0)$.

A repeated-measures ANOVA design was employed, and each participant experienced clear weather, fog weather, and fog weather with fog warning, thus totalizing three trials/scenarios for each one. The clear weather scenario (Figure 5a) represents the baseline group and will be useful for analyses of drivers' default behavior. The other two scenarios (Figure $5 b, c$ ) are expected to enable analyses of the way both fog and CV technologies inside the car change the drivers' behavior. The order of the scenarios was randomly sorted for each participant towards avoiding bias, as well as accommodating the limited time each participant would spend in the simulator and minimizing possible simulator sickness.

A Protection of Human Subjects in Research approval (number 2.611.849) was obtained from the Brazilian National Health Council prior to the experiments. Upon arrival at the laboratory, each participant signed informed consent and filled out a personal information 
questionnaire. They were also instructed on procedures and mechanical operations of the driving simulator. The instructions did not include any detailed information on the experiments that might potentially influence the driving behavior. The participants were asked to drive as normally as they usually do in a real car. Subsequently, they drove an adaptation scenario until they had felt adapted to the simulator and comfortable with the simulation. The adaptation simulation lasted at least $5 \mathrm{~min}$ for each participant and could be repeated as many times as necessary. After the adaptation scenario, the participants drove for approximately $5 \mathrm{~min}$ in each of the three experimental scenarios, with a 2-min interval between them. They were instructed to pull over and stop after they had driven through the data collection segments. The experiment lasted approximately $30 \mathrm{~min}$.

\subsection{Data Analysis}

A two-way repeated-measures ANOVA is often used to compare two or more groups evaluated at different moments. In this research, 3 groups (scenarios) were compared at 2 different moments (before and after the 6th curve). The ANOVA test was applied by Jamovi (version 1.1) software for the analysis of the effect of different scenarios conditions on speed. All follow-up analyses used Tukey test correction for multiple comparisons. Normality was fulfilled with the Shapiro-Wilk test for all scenarios, and descriptive statistics (mean and standard deviation) for speed are shown in Table 1.

Table 1. Speed mean and standard deviation before and after C6 per scenario.

\begin{tabular}{ccccc}
\hline \multirow{2}{*}{ Scenario } & \multicolumn{3}{c}{ Before C6 } & \multicolumn{3}{c}{ After C6 } \\
\cline { 2 - 5 } & Mean & SD * & Mean & SD * $^{*}$ (km) \\
\cline { 2 - 5 } & 92.1 & 6.3 & 77.8 & 10.4 \\
Clear & 88.7 & 10.1 & 68.6 & 8.8 \\
Fog & 78.8 & 16.1 & 57.5 & 10.9 \\
\hline Fog \& CV & & & &
\end{tabular}

${ }^{*} \mathrm{SD}=$ Standard deviation.

\section{Results and Discussion}

\subsection{General Results}

Figure 6 shows the color path of all participants' average speed changes in each scenario- the speed along the curve was not constant and was adjusted according to the curve geometry, as observed by Li et al. [17]. The average speed was higher before and after $\mathrm{C} 6$ in the clear weather scenario compared to other scenarios. The color path figure (Figure 6) is consistent with the graphic displayed in Figure 7, where the comparison of speeds between scenarios is easier. After C6, the speed is significantly decreased in the three scenarios, due to the influence of the road geometry. In presence of fog, the speed decrease was greater in the scenario with $\mathrm{CV}$ warning.

\subsection{Summary Statistics}

The average speeds at which the participants drove under clear weather in the simulator were $92.1 \mathrm{~km} / \mathrm{h}$ before $\mathrm{C} 6$ and $77.8 \mathrm{~km} / \mathrm{h}$ after $\mathrm{C} 6$. The average speeds driven under fog weather were $88.7 \mathrm{~km} / \mathrm{h}$ before C6, and $68.6 \mathrm{~km} / \mathrm{h}$ after C6. Finally, in the fog \& CV scenario, the average driving speeds were $78.8 \mathrm{~km} / \mathrm{h}$ before C6 and $57.5 \mathrm{~km} / \mathrm{h}$ after C6. Table 1 shows the means and standard deviations speeds.

\subsection{Two-Way Repeated Measures ANOVA}

Two-way ANOVA with repeated measures analyzed the average speed variations during the experiment before and after $\mathrm{C} 6$ and its interaction with the scenarios (Within Subjects Effects) shown in Table 2. The scenarios interaction (Between Subjects Effects) was also analyzed and is shown in Table 3. The hypothesis testing in the analysis was based on a 0.05 significance level. 

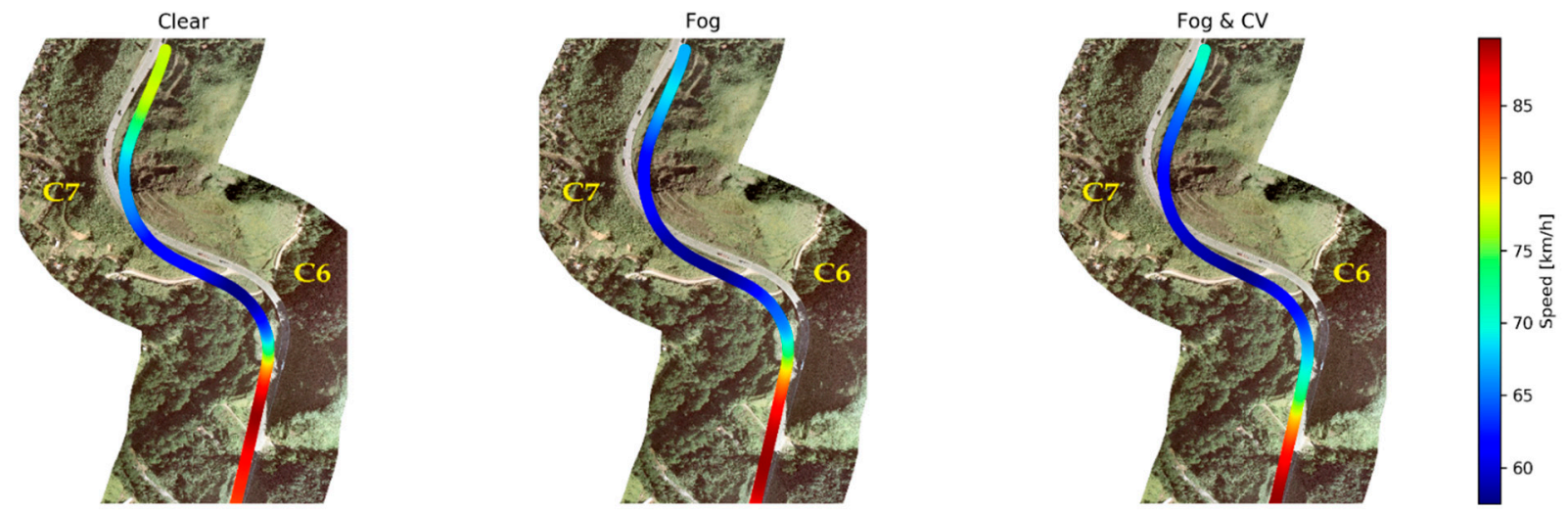

Figure 6. Color path of all participants' average speeds $(\mathrm{km} / \mathrm{h})$ when performing the 6th curve (C6) and 7th curve (C7) in each scenario.

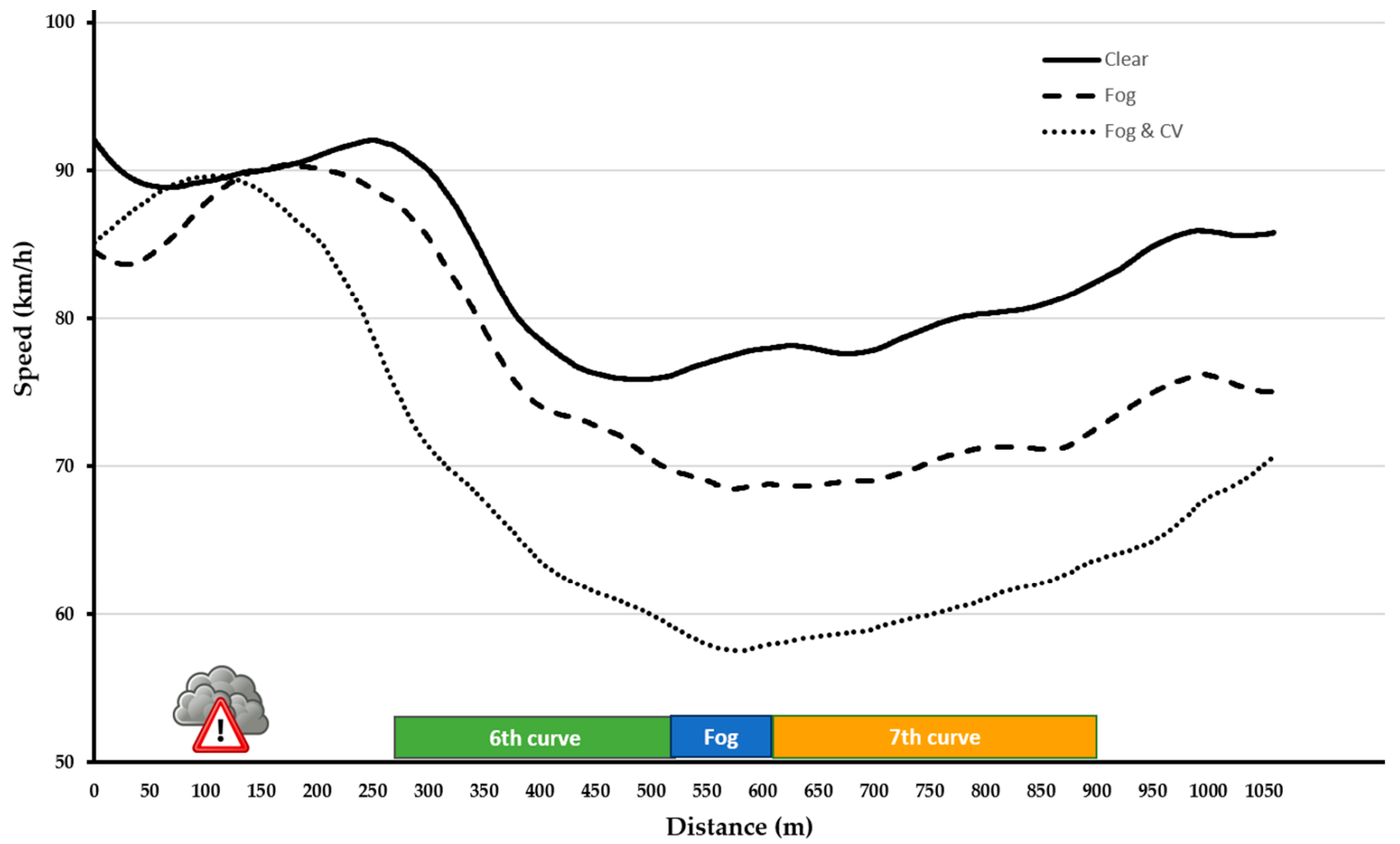

Figure 7. Comparison of all participants' average speeds $(\mathrm{km} / \mathrm{h})$ in each scenario.

Table 2. Repeated Measures ANOVA for within-subjects effects.

\begin{tabular}{|c|c|c|c|c|c|}
\hline Source & Sum of Squares & df & $\begin{array}{l}\text { Mean } \\
\text { Square }\end{array}$ & $\mathbf{F}$ & $p$ \\
\hline C6 moment & 12,984 & 1 & 12,984 & 217.63 & $<0.001$ \\
\hline C6 moment $\times$ Scenario & 830 & 2 & 415 & 6.96 & 0.002 \\
\hline Residual & 4833 & 81 & 59.7 & - & - \\
\hline
\end{tabular}

Note. Type 3 Sums of Squares. $\left(^{*}\right)$ interaction between scenario and moment in 6th curve.

Both Clear/Fog/Fog\&CV $[\mathrm{F}(2,81)=27.1 ; p<0.001]$ and the curve moment (After/Before) $[\mathrm{F}(1,81)=217.63 ; p<0.001]$ significantly influenced the average speed. The analyses also revealed an effect of the interaction between scenario and curve moment on speed $[\mathrm{F}(2,81)=6.96 ; p=0.002]$. Post hoc comparisons were performed with a Tukey test for identifying differences (Table 4 ). 
Table 3. Repeated Measures ANOVA for between-subjects effects.

\begin{tabular}{cccccc}
\hline Source & Sum of Squares & df & Mean Square & F & $p$ \\
\hline Scenario & 9452 & 2 & 4726 & 27.1 & $<0.001$ \\
Residual & 14,146 & 81 & 175 & - & - \\
\hline
\end{tabular}

Note. Type 3 Sums of Squares.

Table 4. Post Hoc Comparisons-C6 moment $\times$ Scenario.

\begin{tabular}{|c|c|c|c|c|c|c|c|c|}
\hline \multicolumn{4}{|c|}{ Comparison } & \multirow[b]{2}{*}{$\mathbf{M}^{*}$} & \multirow[b]{2}{*}{$\mathrm{SE}$} & \multirow[b]{2}{*}{ df } & \multirow[b]{2}{*}{$t$} & \multirow[b]{2}{*}{$p_{\text {tukey }}$} \\
\hline $\begin{array}{c}\text { C6 } \\
\text { Moment }\end{array}$ & Scenario & $\begin{array}{c}\text { C6 } \\
\text { Moment }\end{array}$ & Scenario & & & & & \\
\hline Before & Clear & Before & Fog & 3.41 & 2.89 & 130.6 & 1.178 & 0.847 \\
\hline- & - & Before & Fog \& CV & 13.35 & 2.89 & 130.6 & 4.614 & $<0.001$ \\
\hline- & - & After & Clear & 11.33 & 2.06 & 81.0 & 5.487 & $<0.001$ \\
\hline- & - & After & Fog & 23.57 & 2.89 & 130.6 & 8.149 & $<0.001$ \\
\hline- & - & After & Fog \& CV & 34.60 & 2.89 & 130.6 & 11.960 & $<0.001$ \\
\hline- & Fog & Before & Fog \& CV & 9.94 & 2.89 & 130.6 & 3.436 & 0.010 \\
\hline- & - & After & Clear & 7.92 & 2.89 & 130.6 & 2.738 & 0.075 \\
\hline- & - & After & Fog & 20.17 & 2.06 & 81.0 & 9.769 & $<0.001$ \\
\hline- & - & After & Fog \& CV & 31.19 & 2.89 & 130.6 & 10.783 & $<0.001$ \\
\hline- & Fog \& CV & After & Clear & -2.02 & 2.89 & 130.6 & -0.698 & 0.982 \\
\hline- & - & After & Fog & 10.23 & 2.89 & 130.6 & 3.536 & 0.007 \\
\hline- & - & After & Fog \& CV & 21.25 & 2.06 & 81.0 & 10.295 & $<0.001$ \\
\hline After & Clear & After & Fog & 12.25 & 2.89 & 130.6 & 4.234 & $<0.001$ \\
\hline- & - & After & Fog \& CV & 23.27 & 2.89 & 130.6 & 8.045 & $<0.001$ \\
\hline- & Fog & After & Fog \& CV & 11.02 & 2.89 & 130.6 & 3.811 & 0.003 \\
\hline
\end{tabular}

${ }^{*} \mathrm{M}=$ Mean difference; $\mathrm{SE}=$ Standard Error; $\mathrm{df}=$ Degrees of freedom.

The Post hoc analysis concerned the impact of each scenario's conditions and the curve moment of the measurement (before/after) on the average speed of the participants.

Towards a better understanding of the interaction effect, the changes in the presence/absence of fog and fog warning in each scenario at the beginning of the curve were compared. Before entering $\mathrm{C} 6$ and under clear weather conditions, the participants experienced the same average speed as those in the Fog scenario $(\mathrm{M}=3.41) p=0.847>0.05$, which was expected, since no change occurred between the scenarios, and fog would occur only after the curve. However, before entering $\mathrm{C} 6$, the participants under fog weather condition experienced a different average speed of those in the Fog\&CV scenario $(\mathrm{M}=9.94) p=0.010$ $<0.05$. Furthermore, before entering $\mathrm{C} 6$, the participants under clear weather conditions also experienced a different average speed in comparison to those in the Fog\&CV scenario $(\mathrm{M}=13.35) p<0.001$, possibly indicating the warning led to a speed reduction.

Similarly, the way the presence/absence of fog and fog warning changed in each scenario after C6 was also compared. The participants under clear weather conditions experienced a different average speed in comparison to those in the fog scenario ( $M=12.25)$ $p<0.001$ and those in the Fog\&CV one $(\mathrm{M}=23.27) p<-0.001$. After $\mathrm{C} 6$, the participants under fog condition experienced a different average speed compared to those in the Fog\&CV scenario $(\mathrm{M}=11.02) p=0.003<0.05$. The results show the participants in each scenario drove at different speeds after performing the curve and entering the fog zone (see Figure 8). 


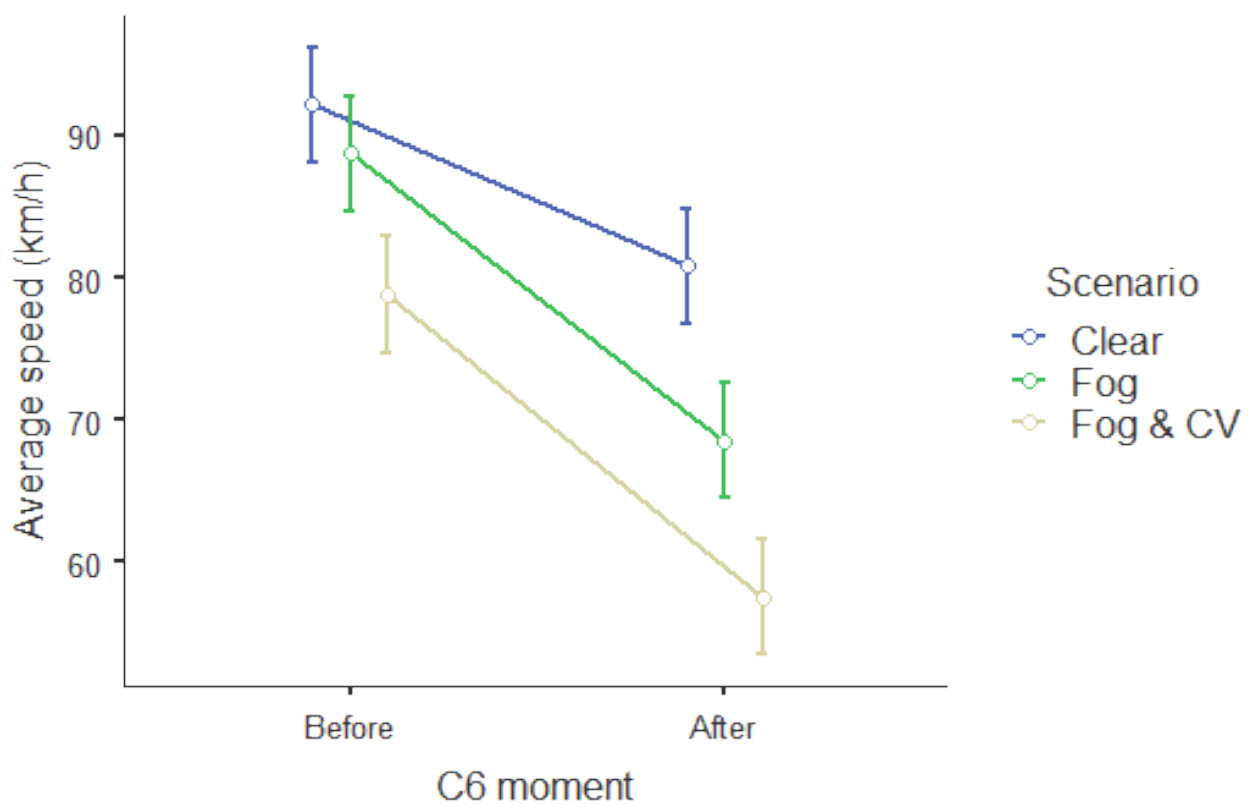

Figure 8. Estimated Marginal Means of average speed $(\mathrm{km} / \mathrm{h})$ in each scenario and curve moment.

\section{Conclusions and Future Research}

This study aims at spurring safety improvements in regions of visibility problems caused by fog, reducing their environmental impact, and preserving drivers' lives. This is one of the first studies that use driving simulators to understand the driving infrastructure's environment under fog in the Brazilian scenario

A two-way ANOVA with repeated measures revealed both fog and in-vehicle fog warning systems can effectively reduce drivers' driving speed. According to a paired comparison with Tukey's correction, the warning shown on the HUD led to an earlier speed reduction in the Fog\&CV scenario. The average driving speeds reduced from $78.8 \mathrm{~km} / \mathrm{h}$ before $\mathrm{C} 6$ to $57.5 \mathrm{~km} / \mathrm{h}$ after $\mathrm{C} 6$, which represents a reduction of approximately $27 \%$. This reduction before and after the curve is more significant than the reductions of $15.5 \%$ and $22.7 \%$ observed in the clear and fog scenarios, respectively. Therefore, a vehicle with an in-vehicle warning system enables drivers to drive at lower speeds in a fog region.

Although in fog weather drivers tend to drive more cautiously and at lower speeds, this is not sufficient to compensate for the hazards imposed by adverse weather. A CV technology would substantially improve road safety since drivers would better adjust speed to enter a fog zone and proceed to a successive curve.

An in-vehicle warning system can improve the speed profile of drivers performing s-curves. Efficient CV technologies would lead to lower-cost changes in road safety in comparison to those in the highway infrastructure.

Connected vehicles technologies can potentially transform our way to drive. However, prior to their broad implementation, several technical challenges must be overcome.

Countries and regions must harmonize their research, standards, policies, and technology; the use of different communications standards, for instance, will hamper the application of connected vehicle technology, since the one used in a certain region may not work in another.

Such technology can also decrease crash risk through the incorporation of drivers' personal characteristics in warning systems, and improve traffic safety under fog conditions. This study was limited to analyzing the drivers' speed profile to detect differences due to the use of a single ADAS. Future research should investigate the effects of different delivery times of warning messages under fog conditions, different designs of the head-up display, and the implementation of multiple ADAS combined. 
Author Contributions: Conceptualization, A.P.C.L. and F.C.; methodology, F.C.; software, F.C.; validation, F.C.; formal analysis, F.C.; investigation, A.P.C.L. and F.C.; resources, A.P.C.L. and F.I.K.J.; data curation, F.C.; writing-original draft preparation, F.C.; writing—review and editing, A.P.C.L. and F.I.K.J.; visualization, F.C.; supervision, A.P.C.L.; project administration, A.P.C.L.; funding acquisition, A.P.C.L. All authors have read and agreed to the published version of the manuscript.

Funding: This research was financially supported by the Coordenação de Aperfeiçoamento de Pessoal de Nível Superior (CAPES; 001).

Institutional Review Board Statement: The study was conducted according to the guidelines of the Declaration of Helsinki, and approved by the Ethical Research Committee of the Faculty of Animal Science and Food Engineering-University of São Paulo (2.611.849).

Informed Consent Statement: Informed consent was obtained from all subjects involved in the study.

Data Availability Statement: No new data were created in this study. Data sharing obtained during the project is not applicable to this article due to legal and privacy issues.

Acknowledgments: The authors acknowledge the University of São Paulo for the support provided to the research activities, the São Paulo Research Foundation (FAPESP) for the financial support, grant 2013/25034-5, the Conselho Nacional de Desenvolvimento Científico e Tecnológico (CNPq), grants 307772/2019-0 and 307772/2019-5, Vi-Grade, Smart Eye and MULTITTECH Engineering.

Conflicts of Interest: The authors declare no conflict of interest. The funders had no role in the design of the study, collection, analysis, or interpretation of data, writing of the manuscript, and decision on the publication of results.

\section{References}

1. Hassan, H.M.; Abdel-Aty, M. Analysis of drivers' behavior under reduced visibility conditions using a Structural Equation Modeling approach. Transp. Res. Part F Traffic Psychol. Behav. 2011, 14, 614-625. [CrossRef]

2. Rosey, F.; Aillerie, I.; Espié, S.; Vienne, F. Driver behaviour in fog is not only a question of degraded visibility-A simulator study. Saf. Sci. 2017, 95, 50-61. [CrossRef]

3. DPRF Dados Abertos das Rodovias Federais. Available online: https://www.prf.gov.br/portal/dados-abertos (accessed on 13 June 2021).

4. Park, J.; Abdel-Aty, M.; Wu, Y.; Mattei, I. Enhancing In-Vehicle Driving Assistance Information Under Connected Vehicle Environment. IEEE Trans. Intell. Transp. Syst. 2019, 20, 3558-3567. [CrossRef]

5. Wu, Y.; Abdel-Aty, M.; Cai, Q.; Lee, J.; Park, J. Developing an algorithm to assess the rear-end collision risk under fog conditions using real-time data. Transp. Res. Part C Emerg. Technol. 2018, 87, 11-25. [CrossRef]

6. Mueller, A.S.; Trick, L.M. Driving in fog: The effects of driving experience and visibility on speed compensation and hazard avoidance. Accid. Anal. Prev. 2012, 48, 472-479. [CrossRef]

7. Broughton, K.L.M.; Switzer, F.; Scott, D. Car following decisions under three visibility conditions and two speeds tested with a driving simulator. Accid. Anal. Prev. 2007, 39, 106-116. [CrossRef]

8. Ni, R.; Kang, J.J.; Andersen, G.J. Age-related declines in car following performance under simulated fog conditions. Accid. Anal. Prev. 2010, 42, 818-826. [CrossRef] [PubMed]

9. Yan, X.; Xue, Q.; Ma, L.; Xu, Y. Driving-simulator-based test on the effectiveness of auditory red-light running vehicle warning system based on time-to-collision sensor. Sensors 2014, 14, 3631-3651. [CrossRef] [PubMed]

10. Wu, Y.; Abdel-Aty, M.; Park, J.; Selby, R.M. Effects of real-time warning systems on driving under fog conditions using an empirically supported speed choice modeling framework. Transp. Res. Part C Emerg. Technol. 2018, 86, 97-110. [CrossRef]

11. Liu, J.; Khattak, A.J. Delivering improved alerts, warnings, and control assistance using basic safety messages transmitted between connected vehicles. Transp. Res. Part C Emerg. Technol. 2016, 68, 83-100. [CrossRef]

12. Boyle, L.N.; Mannering, F. Impact of traveler advisory systems on driving speed: Some new evidence. Transp. Res. Part C Emerg. Technol. 2004, 12, 57-72. [CrossRef]

13. Al-Ghamdi, A.S. Experimental evaluation of fog warning system. Accid. Anal. Prev. 2007, 39, 1065-1072. [CrossRef]

14. Zhao, X.; Xu, W.; Ma, J.; Li, H.; Chen, Y.; Rong, J. Effects of connected vehicle-based variable speed limit under different foggy conditions based on simulated driving. Accid. Anal. Prev. 2019, 128, 206-216. [CrossRef]

15. Chang, X.; Li, H.; Qin, L.; Rong, J.; Lu, Y.; Chen, X. Evaluation of cooperative systems on driver behavior in heavy fog condition based on a driving simulator. Accid. Anal. Prev. 2019, 128, 197-205. [CrossRef]

16. Wu, Y.; Abdel-Aty, M.; Park, J.; Zhu, J. Effects of crash warning systems on rear-end crash avoidance behavior under fog conditions. Transp. Res. Part C Emerg. Technol. 2018, 95, 481-492. [CrossRef]

17. Li, X.; Yan, X.; Wong, S.C. Effects of fog, driver experience and gender on driving behavior on S-curved road segments. Accid. Anal. Prev. 2015, 77, 91-104. [CrossRef] [PubMed]

18. Milosević, S.; Milić, J. Speed perception in road curves. J. Safety Res. 1990, 21, 19-23. [CrossRef] 
19. Lucas, F.R.; Russo, L.E.A.; Kawashima, R.S.; Figueira, A.C.; Larocca, A.P.C.; Kabbach, F.I., Jr. Use of driving simulators Applied to road safety project. Bol. Ciencias Geod. 2013, 19, 341-352. [CrossRef]

20. Santos, M.I.d.; Oliveira, P.T.M.e.S.d.; Ribeiro, R.L.; Larocca, A.P.C.; Kabbach Junior, F.I. Conceito, configuração e aplicação de um simulador de direção no Brasil-Estudo de caso. Transportes 2017, 25. [CrossRef]

21. Vieira, F.S.; Larocca, A.P.C. Drivers' speed profile at curves under distraction task. Transp. Res. Part F Traffic Psychol. Behav. 2017, 44, 12-19. [CrossRef]

22. Larocca, A.P.C.; Ribeiro, R.L.; da Cruz Figueira, A.; Lulio, L.C.; Rangel, M.A.C. Analysis of perception of vertical signaling of highways by drivers in a simulated driving environment. Transp. Res. Part F Traffic Psychol. Behav. 2018, 58, 471-487. [CrossRef]

23. Figueira, A.C.; Larocca, A.P.C. Analysis of the factors influencing overtaking in two-lane highways: A driving simulator study. Transp. Res. Part F Traffic Psychol. Behav. 2020, 69, 38-48. [CrossRef]

24. Figueira, A.C.; Larocca, A.P.C. Proposal of a driver profile classification in relation to risk level in overtaking maneuvers. Transp. Res. Part F Traffic Psychol. Behav. 2020, 74, 375-385. [CrossRef]

25. de Campos, C.I.; Marcomini, L.A.; Panice, N.R.; Piva, F.J.; Larocca, A.P.C. Perception analysis of highway quality of service using a driving simulator and eye tracking system. Transportes 2020, 28, 165-179. [CrossRef]

26. Calsavara, F.; Kabbach Junior, F.I.; Larocca, A.P.C. Effects of Fog in a Brazilian Road Segment Analyzed by a Driving Simulator for Sustainable Transport: Drivers' Visual Profile. Sustainability 2021, 13, 9448. [CrossRef]

27. Abdel-Aty, M.; Ekram, A.A.; Huang, H.; Choi, K. A study on crashes related to visibility obstruction due to fog and smoke. Accid. Anal. Prev. 2011, 43, 1730-1737. [CrossRef] [PubMed]

28. Denatran-Departamento Nacional de Trânsito Manual de Identificação, Análise e Tratamento dos Pontos Negros. Dep. Nac. Trânsito 1987, 2, 127.

29. DNIT-Departamento Nacional de Infraestrutura de Transportes PNCT—Plano Nacional de Contagem de Tráfego. Available online: http:/ / servicos.dnit.gov.br/dadospnct/ContagemContinua (accessed on 15 January 2021). 